\title{
Functional evaluation of DNA repair in human biopsies and their relation to other cellular biomarkers
}

\author{
Jana Slyskova ${ }^{1,2}$, Sabine A. S. Langie ${ }^{3,4}$, Andrew R. Collins ${ }^{5}$ and Pavel Vodicka ${ }^{1,2}$ \\ ${ }^{1}$ Department of Molecular Biology of Cancer, Institute of Experimental Medicine ASCR, Prague, Czech Republic \\ ${ }^{2}$ Institute of Biology and Medical Genetics, First Faculty of Medicine, Charles University, Prague, Czech Republic \\ ${ }^{3}$ Centre for Brain Ageing and Vitality, Institute for Ageing and Health, Human Nutrition Research Centre, Newcastle University, Newcastle upon Tyne, UK \\ ${ }^{4}$ Environmental Risk and Health Unit, Flemish Institute for Technological Research (VITO), Mol, Belgium \\ ${ }^{5}$ Department of Nutrition, University of Oslo, Oslo, Norway
}

\section{Edited by:}

Geoff Clark, University of Louisville, USA

\section{Reviewed by:}

Alessandra Montecucco, Consiglio

Nazionale delle Ricerche, Italy

George A. Garinis, Institute of

Molecular Biology and

Biotechnology-FORTH and

University of Crete, Greece

${ }^{*}$ Correspondence:

Jana Slyskova, Department of Molecular Biology of Cancer,

Institute of Experimental Medicine ASCR, Videnska 1083, 14220

Prague, Czech Republic

e-mail: j.slyskova@gmail.com
Thousands of DNA lesions are estimated to occur in each cell every day and almost all are recognized and repaired. DNA repair is an essential system that prevents accumulation of mutations which can lead to serious cellular malfunctions. Phenotypic evaluation of DNA repair activity of individuals is a relatively new approach. Methods to assess base and nucleotide excision repair pathways (BER and NER) in peripheral blood cells based on modified comet assay protocols have been widely applied in human epidemiological studies. These provided some interesting observations of individual DNA repair activity being suppressed among cancer patients. However, extension of these results to cancer target tissues requires a different approach. Here we describe the evaluation of BER and NER activities in extracts from deep-frozen colon biopsies using an upgraded version of the in vitro comet-based DNA repair assay in which 12 reactions on one microscope slide can be performed. The aim of this report is to provide a detailed, easy-to-follow protocol together with results of optimization experiments. Additionally, results obtained by functional assays were analyzed in the context of other cellular biomarkers, namely single nucleotide polymorphisms and gene expressions. We have shown that measuring DNA repair activity is not easily replaceable by genomic or transcriptomic approaches, but should be applied with the latter techniques in a complementary manner. The ability to measure DNA repair directly in cancer target tissues might finally answer questions about the tissue-specificity of DNA repair processes and their real involvement in the process of carcinogenesis.

Keywords: in vitro comet-based DNA repair assay, base excision repair, nucleotide excision repair, human solid tissue, methodological report

\section{INTRODUCTION}

The ability of cells to protect against a large variety of DNA disruptions is a vital process for living organisms. Base excision repair (BER) and nucleotide excision repair (NER) belong to the subgroup of DNA repair mechanisms that are active on structurally modified DNA bases. The biological significance of both pathways is highlighted by the well-known association of BER or NER deficiency with the incidence of inherited (Cleaver et al., 2009) and sporadic types of cancer (Slyskova et al., 2012a). Moreover, the individual's BER and NER capacity is expected to have an influence on the response to anti-neoplastic drug treatment (Pallis and Karamouzis, 2010; Lord and Ashworth, 2012). Therefore, being able to screen an individual's repair capacity may represent a step toward risk assessment and individualized cancer therapy.

Our current knowledge of DNA repair indicates that this process involves many genes that have to work in a synchronized and coordinated way. The simultaneous participation of other processes such as DNA damage signaling, cell cycle controls, and maybe even other (un)known genes, makes DNA repair a multigene and multipathway process. There is a body of evidence concerning different levels of DNA repair gene regulation. The majority of DNA repair genes are polymorphic in the human population, with as yet uncharacterized functional consequences (Ricceri et al., 2012). Therefore, DNA sequence analyses cannot be sufficiently informative for predicting DNA repair activity. Gene expression has been shown to be a misleading source of information, because changes in mRNA levels do not necessarily reflect changes in enzyme activity and vice versa (Damia et al., 1998; Vogel et al., 2000; Paz-Elizur et al., 2007; Stevens et al., 2008; Hanova et al., 2011; Slyskova et al., 2012a,b). This is due to extensive post-transcriptional and post-translational modifications and protein-protein interactions that take part in regulating the activity of repair proteins (Fan and Wilson, 2005; Hu and Gatti, 2011; Nouspikel, 2011). Moreover, DNA repair is a multifactorial process that is modulated not exclusively by genetic background, but, to a certain extent, might be regulated by environmental and lifestyle factors (Wu et al., 2006; Collins et al., 2012). Measuring the true phenotypic endpoint seems in this context to be the most informative, straightforward, and perhaps the most reliable way of characterizing the DNA repair processes. 
Both excision pathways follow a common pattern: recognition of the DNA lesion, excision of the damage, and resynthesis of the removed sequence. Transient strand breaks (SBs) are generated as intermediates during both repair pathways, which make BER and NER easily measurable on the functional level by methods based on the comet assay. This assay is a sensitive technique for quantification of SBs in DNA which is applicable not only to measure basal DNA damage, but also in a modified form for measuring DNA repair incision activity. So far, human blood has been used in the majority of studies examining DNA repair activity, since blood is usually the only tissue that can be sampled from healthy subjects. Methods for evaluation of BER and NER from peripheral blood cells are currently well-established (Collins et al., 2001; Langie et al., 2006). However, often it is important to consider the level of DNA repair in particular organs, especially when analysing DNA repair activity in association with tissue-specific diseases. Although it might be logistically complicated in most cases, from cancer patients, there is still a possibility to obtain not only peripheral blood, but also surgically resected normal or tumor tissue. Langie et al. (2010, 2011) have published protocols modified for assessment of DNA repair activity in animal solid tissues; however, a methodological approach for its evaluation in human biopsies has not yet been optimized. Moreover, despite the undeniable biological significance of DNA repair, DNA repair activity is still not routinely included as a biomarker in human biomonitoring studies. This is partially due to the fact that it is a relatively laborious method, especially when large numbers of samples are analyzed.

This text presents a detailed comet assay-based protocol for measuring BER- and NER-specific incision activity in vitro from deep-frozen human solid tissues, covering all its optimization steps. The protocol has been recently applied for the first time on colorectal cancer biopsies (Slyskova et al., 2012b). In order to increase the applicability of this approach to large-scale epidemiological studies, the 12-minigel format (12 agarose minigels per microscopic slide) instead of the conventional format (one or two large agarose gels per slide) has been applied. In addition, the relationship between the detected DNA repair activity and other biomarkers (single nucleotide variants in and expression of DNA repair genes) routinely measured in human biomonitoring studies is also discussed.

\section{MATERIALS AND METHODS STUDY POPULATION AND COLLECTION OF BIOLOGICAL SPECIMEN}

The study was conducted on colorectal tissues collected from 70 CRC patients at the surgical resection of the tumor. Patients were recruited between 2009 and 2011 in Thomayer Hospital (Prague), General University Hospital (Prague), and Teaching Hospital and Medical School of Charles University (Pilsen). All patients gave informed consent. Ethics approval was granted by appropriate committees of the three hospitals. The group of patients included 53 men and 17 women with a mean age of $66.2 \pm 10.6$ years. The clinical stage of patients at diagnosis was classified according to the tumor-node-metastasis (TNM) system. Seven patients were diagnosed with TNM stage I (10\%), 29 as stage II (41.4\%), 15 as stage III (21.4\%), and 19 as stage IV (27.2\%). All patients had adenocarcinomas; 44 patients had tumor localized in the colon $(62.9 \%)$ and 26 in the rectum (37.1\%). In $12(17.2 \%)$ patients, tumors were of well-differentiated grade, in $47(67.1 \%)$ moderately differentiated and in 11 patients (15.7\%) poorly differentiated. Eleven rectal cancer patients (15.7\%) received neoadjuvant therapy prior to surgery. Tumor tissue and adjacent healthy colon/rectal tissue $(5-10 \mathrm{~cm}$ distant from the tumor) were resected from all patients. Colon biopsies were briefly washed in PBS and snap frozen immediately after the resection and further stored at $-80^{\circ} \mathrm{C}$. Prior to tissue processing, histological analysis was carried out to assess the proportion of tumor cells in tumor tissues and to rule out the presence of neoplastic cells in the normal mucosal tissues. The cut-off point was set to $80 \%$ of tumor or normal cells in the sample, respectively. Samples were embedded in optimal cutting temperature compound (Sakura Finetek), and cut with a Leica CM 1850 cryostat. Five $\mu \mathrm{m}$ thick serial sections were fixed in $90 \%$ ethanol on microscope slides and stained with $1 \%$ cresyl violet acetate (Sigma-Aldrich), dehydrated with ethanol, dried, and inspected using a Leica DM6000 microscope (Leica). Due to various logistical reasons, not all patients could be analyzed for all the studied parameters. Therefore, each particular analysis is further specified for actual number of cases for whom analysis was carried out.

\section{IN VITRO COMET-BASED DNA REPAIR ASSAY Principle of the assay}

Protein extracts isolated from human tissues were incubated with substrate DNA in the form of nucleoids, containing artificially induced lesions known to be repaired specifically by either the BER or NER pathway. The photosensitizer Ro 19-8022, in the interaction with visible light, gives rise to oxidative DNA damage (predominantly to 8 -oxoguanines; 8 -oxoG) that are specifically recognized by the BER machinery. Alternatively, nucleoids containing ultraviolet light (UV)-induced cyclobutane pyrimidine dimers (CPD) and 6-4 photoproducts represent the substrate for the NER pathway. The level of induced lesions can be detected by enzymes of bacterial or viral origin, which serve as positive controls in each experiment. Two types of enzymes were used, formamidopyrimidine DNA glycosylase (Fpg) as a prokaryotic analog of human OGG1 that recognizes oxidized purines, and T4 Endonuclease V (Endo V) produced by T4 bacteriophage, recognizing UV-induced CPD. In addition, each experiment included a negative control, namely lesion-containing substrate DNA incubated with reaction buffer to assess the background damage together with buffer-induced damage. Furthermore, each protein extract was measured for (i) specific repair activity (i.e., extract incubated with lesion-containing DNA) and (ii) non-specific endonuclease activity (i.e., specificity control; extract incubated with lesion-free DNA). To be able to record only specific activity of repair proteins, the non-specific endonuclease activity of the protein extract was subtracted. The frequency of DNA SBs, generated during incision of lesions, reflects the DNA repair activity of the extract.

\section{Substrate DNA}

In this protocol, the cellular source of substrate DNA consisted of peripheral blood mononuclear cells (PBMC) and humanderived lymphoblastoid cells (TK6), though in principle any 
other mammalian cells in suspension could be used. Cells should be controlled for low basal level of SBs (ideally not higher than $10 \%$ DNA in tail) and such was the case in this study. PBMC were separated on Histopaque-1077 (Sigma-Aldrich), counted, evaluated by trypan blue exclusion and suspended in ice-cold PBS. TK6 cells were grown in RPMI medium supplemented with $10 \%$ heat-inactivated fetal calf serum, $0.2 \mathrm{mg} / \mathrm{mL}$ sodium pyruvate, $2 \mathrm{mM}$ L-glutamine, $100 \mathrm{U} / \mathrm{mL}$ penicillin, and $0.1 \mathrm{mg} / \mathrm{mL}$ streptomycin (Sigma-Aldrich). Cells were counted and suspended in ice-cold PBS. For BER, PBMC were treated with $2 \mu \mathrm{M}$ Ro 19-8022 (Hoffmann-La Roche) for $5 \mathrm{~min}$, and irradiated on ice at $33 \mathrm{~cm}$ distance from a $500 \mathrm{~W}$ halogen lamp. For NER, TK6 cells were irradiated with $5 \mathrm{Jm}^{-2}$ of UVC (50 s at $\left.0.1 \mathrm{Jm}^{-2} \mathrm{~s}^{-1}\right)$. Lesion-free PBMC and TK6 cells were prepared in parallel. Cells were aliquoted at $5 \times 10^{5}$ in $0.5 \mathrm{~mL}$ of freezing medium (RPMI 1640, 20\% fetal bovine serum, $0.2 \%$ antibiotics, $10 \%$ DMSO, Sigma-Aldrich) and frozen slowly to $-80^{\circ} \mathrm{C}$. Before each experiment, cells were thawed by adding $1 \mathrm{~mL}$ of cold PBS, spun at $400 \mathrm{~g}, 5 \mathrm{~min}, 4^{\circ} \mathrm{C}$, and suspended in $400 \mu \mathrm{L}$ of PBS. An $80 \mu \mathrm{L}$ aliquot of the cell extract was mixed with $260 \mu \mathrm{L}$ of $1 \%$ LMP agarose to reach the desired concentration of cells $(\sim 300-600$ cells per minigel). Using a multi-dispensing pipette, twelve $5 \mu \mathrm{L}$ minigels of cells in agarose were placed on each microscope slide. Cells embedded in agarose underwent lysis for $1 \mathrm{~h}$ in $2.5 \mathrm{M} \mathrm{NaCl}$, $100 \mathrm{mM}$ EDTA, $10 \mathrm{mM}$ Tris, $250 \mathrm{mM} \mathrm{NaOH}, 1 \%$ Triton X$100, \mathrm{pH} 10$. Before incubation with protein extracts, slides were washed twice for $5 \mathrm{~min}$ with buffer B ( $45 \mathrm{mM}$ HEPES, $0.25 \mathrm{mM}$ EDTA, $0.3 \mathrm{mg} / \mathrm{mL}$ BSA, 2\% glycerol, $\mathrm{pH} 7.8$ ) and placed in incubation chambers (Severn Biotech) (Shaposhnikov et al., 2010).

\section{Protein extracts preparation}

Tissue resections were weighed and ground while frozen, and 30$50 \mathrm{mg}$ aliquots were stored at $-80^{\circ} \mathrm{C}$. For extraction, a volume of $100 \mu \mathrm{L}$ of buffer A ( $45 \mathrm{mM}$ HEPES, $0.4 \mathrm{M} \mathrm{KCl,} 1 \mathrm{mM}$ EDTA, $0.1 \mathrm{mM}$ DTT, $10 \%$ glycerol, $\mathrm{pH} 7.8$ ) was added to every $50 \mathrm{mg}$ of ground tissue. Samples were vortexed, snap frozen, and $30 \mu \mathrm{L}$ of $1 \%$ Triton X-100 in buffer A added per $100 \mu \mathrm{L}$. Protein concentration was measured by a fluorescamine assay (Sigma-Aldrich), on a NanoDrop 3300 (Thermo Scientific). Undiluted extracts were kept at $-80^{\circ} \mathrm{C}$. Before the incubation reaction, on the day of use, extracts were diluted to a protein concentration of $3 \mathrm{mg} / \mathrm{mL}$ in buffer $\mathrm{A}$ in a final volume of $50 \mu \mathrm{L}$ and mixed with 4 volumes of buffer B.

\section{BER-specific reaction}

A $30 \mu \mathrm{L}$ aliquot of extract was added to each minigel in the incubation chamber. Each extract was incubated with Ro-treated as well as non-treated PBMC (used for background subtraction). Incubation time was $20 \mathrm{~min}$, at $37^{\circ} \mathrm{C}$ in a humid environment. Fpg was used as a positive control. For a negative control substrate DNA was incubated with buffer A + buffer B in a 1:4 ratio. Each experimental point was performed in duplicate. In optimization experiments, PARP inhibitor ABT-888 (Selleckchem) was added to the extract at a concentration of $5 \mu \mathrm{M}$ to test the effect of inhibiting the post-incision phase of BER.

\section{NER-specific reaction}

For the NER-specific assay, the protein extract was enriched with adenosine- $5^{\prime}$-triphosphate at a final concentration of $2.5 \mathrm{mM}$. A $30 \mu \mathrm{L}$ aliquot of extract was added to each minigel in the incubation chamber. Each extract was in parallel incubated for $30 \mathrm{~min}$ with UV-treated and non-treated TK6 cells (used for background subtraction). UV substrate incubated with Endo V was used as positive control and 1:4 buffer A + buffer B as negative control. In optimization experiments, aphidicolin (DNA polymerase delta inhibitor; Sigma-Aldrich) at a concentration of $2.5 \mu \mathrm{M}$ was added to the extract to test the effect of DNA resynthesis inhibition.

\section{Single cell gel electrophoresis}

After the incubation period, the protocol followed was the same as previously described for the comet assay (Olive and Banath, 2006). In brief: slides were treated for $20 \mathrm{~min}$ under alkaline conditions (0.3 M NaOH, $1 \mathrm{mM}$ EDTA, pH 12) to allow DNA denaturation and subsequently electrophoresed for $20 \mathrm{~min}$ at $1.3 \mathrm{~V} / \mathrm{cm}$. Washing followed, with PBS, then $\mathrm{H}_{2} \mathrm{O}$ and finally ethanol, each for $10 \mathrm{~min}$. Slides were stained with SYBRGold (Invitrogen) at the concentration recommended by the manufacturer in a bath at $4^{\circ} \mathrm{C}$ with agitation. After $40 \mathrm{~min}$, SYBRGold solution was removed and the slides rinsed twice with water and left to dry at room temperature. On the day of analysis gels were hydrated by adding a drop of water on top of each minigel and covered with a coverslip. The comets were evaluated by visual scoring performed exclusively by one person (Azqueta et al., 2011). Comets were analyzed by a Nikon fluorescence microscope using 5 classes of comets from class 0 (undamaged, no discernible tail) to class 4 (almost all DNA in tail, insignificant head). Hundred comets were selected at random for each sample (50 comets per duplicate gel), so the overall score from one sample ranged from 0 to 400 arbitrary units. Final DNA repair activity was calculated as the difference between scores for treated substrate incubated with extract and non-treated substrate incubated with extract. (Visual scoring was preferred only because of technical problems with image analysis software at the time of the study; however, scoring with computerized software is equally recommended).

\section{GENOTYPING}

Single nucleotide polymorphisms (SNPs) were selected according to their (i) location in a gene involved in a pre-incision complex of BER or NER whose activity is detectable by DNA repair assays, (ii) minor allelic frequency $>5 \%$, and (iii) predicted damaging or deleterious effect on protein function by SIFT or PolyPhen algorithms (Xi et al., 2004). DNA was isolated from total blood by the phenol-chloroform method. SNPs were detected by TaqMan ${ }^{\circledR}$ SNP Genotyping Assays based on allelespecific TaqMan ${ }^{\circledR}$ MGB probes plus PCR primers and analyzed on Applied Biosystems 96-well real-time PCR instrumentation (Life Technologies). Functional SNPs in BER genes were represented by OGG1 Ser326Cys (rs 1052133). Selected SNPs within NER genes involved XPA G23A (rs 1800975), XPC Ala499Val (rs 2228000) and Lys939Gln (rs 2228001), XPD Lys751Gln (rs 13181), XPG Asn1104His (rs 17655) and XPF Arg415Gln (rs 1800067). 


\section{REVERSE TRANSCRIPTION qPCR}

Tissue samples were homogenized in the MagNA Lyser (Hoffmann-La Roche). AllPrep DNA/RNA mini kit (Qiagen) was used to isolate nucleic acids. Total RNA was measured on ASP-3700 Spectrophotometer (Avans-Biotechnology) for quantity and OD260/280 ratio. RNA integrity number (RIN) was checked using Agilent Bioanalyzer 2100, with RNA 6000 Nano Assay (Agilent Technologies). cDNA was synthesized from 500 ng of RNA using a RevertAidTM First strand cDNA synthesis kit (Thermo Scientific) using random hexamers and following manufacturer's instructions. cDNA was diluted to 10 $\mathrm{ng} / \mu \mathrm{L}$ and preamplified for 18 cycles on a CFX96 Real Time PCR Instrument (Biorad) according to the manufacturer's protocol. qPCR was performed using the high-throughput platform BioMark $^{\mathrm{TM}}$ HD System (Fluidigm). Ten $\mu \mathrm{L}$ of reaction mix contained $1 \mu \mathrm{L}$ of $20 \times$ diluted preamplified cDNA, $2.5 \mu \mathrm{L}$ of Taqman Universal Mastermix II without UNG (Life Technologies), $5 \mu \mathrm{L}$ of primer/probe assays with Perfect Probe ${ }^{\mathrm{TM}}$ (Primer Design) at a final concentration of $300 \mathrm{nM}, 2.5 \mu \mathrm{L}$ of $2 \times$ Assay loading reagent and $0.25 \mu \mathrm{L}$ of $20 \times$ GE sample loading reagent (Fluidigm) and $1.25 \mu \mathrm{L}$ of water. Cycling conditions for qPCR were: $95^{\circ} \mathrm{C}$ for $10 \mathrm{~min}, 45$ cycles of $95^{\circ} \mathrm{C}$ for $15 \mathrm{~s}$ and $50^{\circ} \mathrm{C}$ for $60 \mathrm{~s}$. TOP1 and $18 S$ rRNA were reference genes selected from a geNorm ${ }^{\mathrm{TM}}$ reference genes selection kit (Primer Design) by Normfinder algorithm (GenEx Enterprise software). Data were collected from one $48 \times 48$ array. Data were normalized to reference genes, converted to relative quantities and transformed to $\log 2$ scale.

\section{STATISTICAL ANALYSIS}

Statistical analysis was performed by SPSS Statistics 18 (IBM) and by GenEx Enterprise (MultiD) softwares. The distribution of investigated parameters was controlled by Kolmogorov-Smirnov test. Expression data were logarithmically transformed to achieve a normal distribution. Two-tailed T-test or ANOVA for differences between groups for normally distributed data was employed and correlations determined by a Pearson's test. When data were not distributed accordingly to a Gaussian curve, non-parametric tests of Kruskal-Wallis, Mann-Whitney or Spearman's correlation coefficient were used. All statistical tests were performed at a $95 \%$ confidence level.

\section{RESULTS AND DISCUSSION \\ OPTIMIZATION OF THE BER- AND NER-SPECIFIC ASSAYS An advanced medium-throughput 12-minigel format}

In order to be able to process a larger number of samples and to suppress the effect of inter-experimental variability, we have utilized the 12-minigel format that was introduced by Shaposhnikov et al. (2010) and is demonstrated in Figure 1. The comparability of the new 12-minigel approach (12 minigels of $5 \mu$ l agarose per slide) with the conventional 2-gel format (2 large gels of $70 \mu \mathrm{l}$ agarose per slide) was tested by Azqueta et al. (2012). Therefore, we have directly optimized the BER- and NER-repair assays for a 12-minigel format, without any additional testing.

The inter-experimental variability given by the 12 -minigel format was low, with the coefficient of variation between 7 independent experiments being $7.7 \%$ for both BER and NER (calculated from the negative and positive control, data not shown). This suggests that only up to $8 \%$ of variability might be attributed to inter-experimental variations. The 12-minigel format, with its 6-times higher yield of analyzed samples per microscopic slide, significantly increases the applicability of repair assays to human epidemiological studies. Sixteen samples can be optimally run for both assays in one experiment, using only 9 microscopic slides and 9 incubation chambers (see scheme displayed in Figure 1). This capacity is not limited by the dimensions of the electrophoretic tank, as is usually the case with the 2-gel format. Another advantage is that the new format requires considerably lower numbers of substrate cells. Instead of $\sim 3000$ substrate cells per gel, the 12-minigel format requires only a tenth of this quantity.

\section{Precision of the assays}

To test repeatability of the assays, we have measured 25 samples in two independent experiments and compared the results. As shown in Figure 2, the inter-experimental variation is negligible and both assays are repeatable with high reliability $(p \leq 0.001)$.

The assays were subsequently tested for the ability to recognize protein extracts deficient in the incision step of repair. For that purpose, extracts from OGG1- and XPG-deficient cells were isolated and their activity compared with the extracts isolated from cells of the same origin but expressing both genes. Figure 3 presents observed results in comparison to positive and negative controls, as described in detail in BER- and NERspecific reaction sections. While protein extracts from wild-type cells showed activity significantly higher than activity measured for knock-out cells (BER: $p=0.007$, NER: $p=0.019$ ), the low activity of knock-out cells was not different from the unspecific activity of buffer only (BER: $p=0.44$, NER: $p=0.39$ ). Both assays confirmed a sensitivity to distinguish biological variability.

\section{Dependence of protein extract activity on protein concentration}

We prepared tissue extract dilutions in the range 0 to $18 \mathrm{mg} / \mathrm{mL}$ protein content and measured the corresponding activity. Surprisingly, the relation between protein concentration and activity of the extract was not (log-)linear (higher protein amount corresponding with higher activity), but instead exhibited an increase of incision activity reaching its maximum at a protein concentration of $3 \mathrm{mg} / \mathrm{mL}$, followed by a drop of activity with further increasing content of proteins (Figure 4). At the concentration point of $3 \mathrm{mg} / \mathrm{mL}$ the ratio between lesion-specific activity and non-specific endonuclease activity of the extract was the highest and in favor of the former. Another confounder would be represented by the ratio between protein amount and accessibility of DNA lesions. Too high protein concentration leads to saturation of the reaction. However, protein concentration optimal for the assays was shown to be tissue-specific, as studied on animal tissues (Langie et al., 2010, 2011), and therefore the concentration set by us is not generally applicable. The optimal concentration should be tested by each user of the assay on particular biological samples. Time of incubation is also a variable that can be recommended, but anyway should be pre-tested on each particular substrate DNA with specific extracts. 

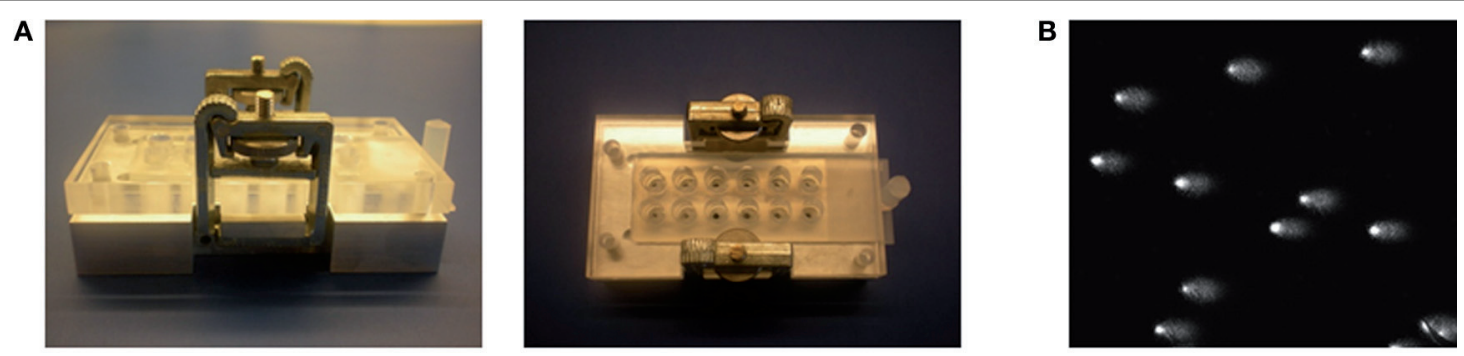

C

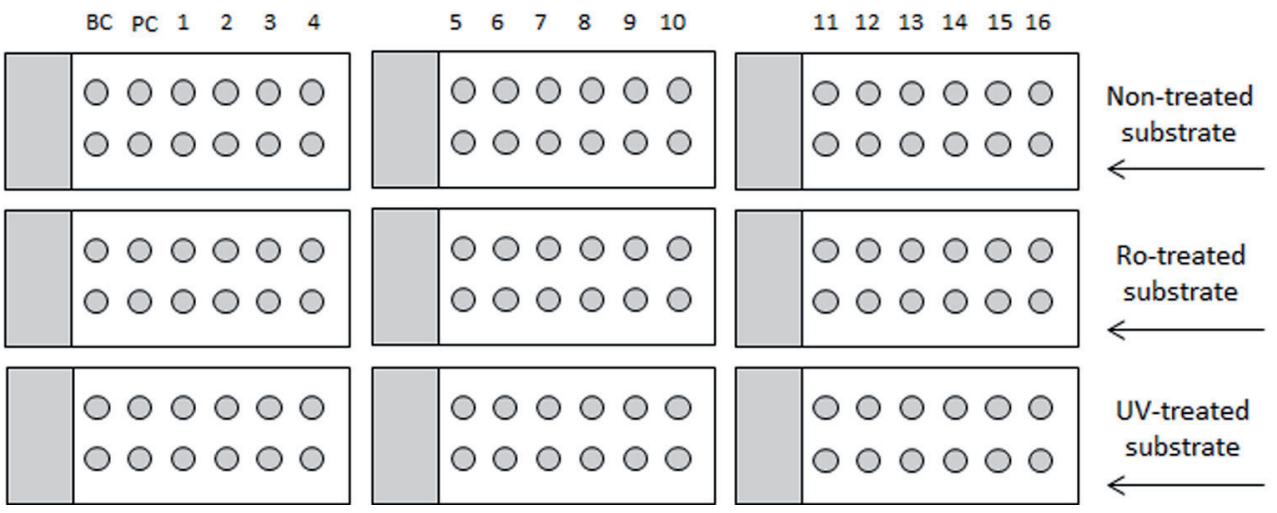

FIGURE 1 | Medium-throughput comet assay format and layout of the experiment. (A) Device for 12-minigel format, (B) image of comets, and (C) a schematic example of an experiment, using 16 different extracts, background control with buffer only (BC) and a positive control with specific enzyme (PC). The experimental layout with 9 microscope slides is applicable only if the same substrate cell-type is used in each assay, so that the same non-treated cells can be used for both.
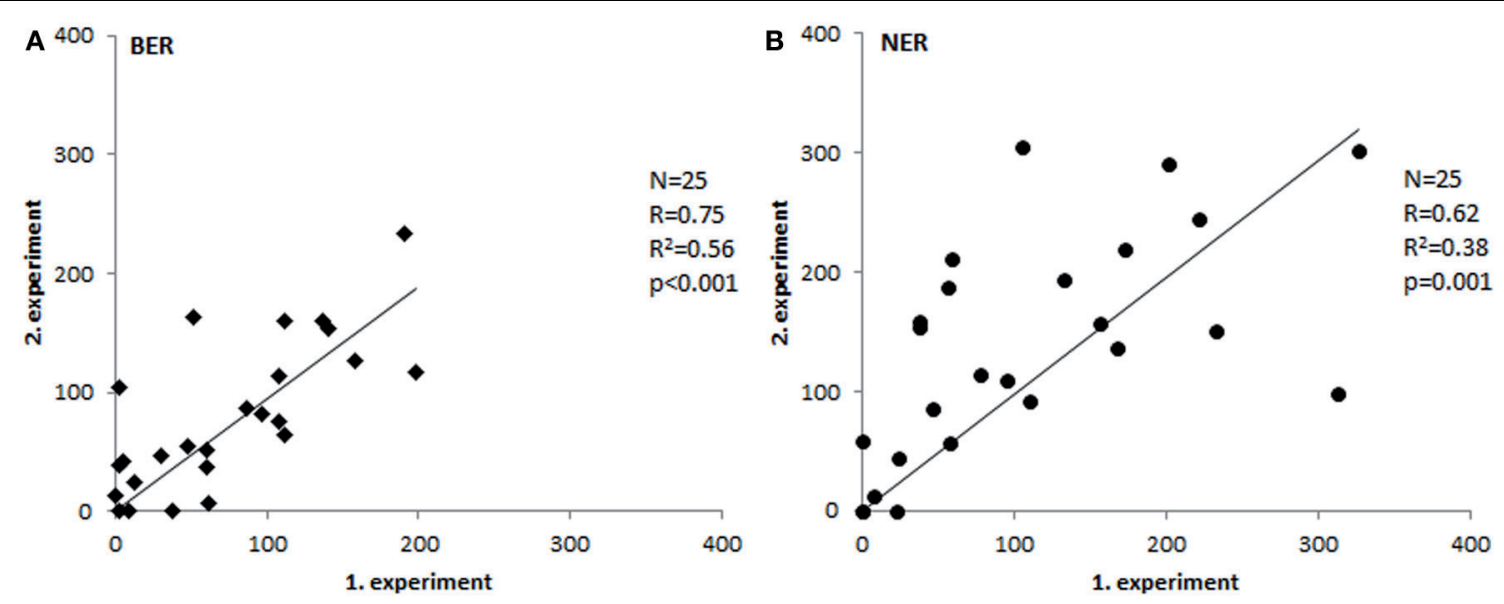

FIGURE 2 | Inter-experimental variability. Comparison of tissue extract activities measured in two separate experiments (Spearman's correlation coefficient). Paired $T$-test $p$-values were 0.58 for BER (A) and 0.1 for NER (B).

\section{Do intermediate SBs reflect the incision activity?}

To test the postulate that SBs measured in the assays are generated specifically by the incision activity of the protein extract, we have used specific agents to inhibit post-incision phase of the repair processes. ABT-888 is a well-known inhibitor of the Poly(ADP)-ribose polymerase (PARP) and has therefore been used in the BER assay. The post-incision NER phase was blocked by aphidicolin (APC), inhibiting the function of polymerase delta. On adding the specific inhibitors, all SBs generated by incision activity are expected to remain "open." As Figure 5 documents, the tissue extracts correspond in $85-88 \%$ of their activities irrespective of the presence of the inhibitors. Thus, BER and NER assays detect specifically the incision step of the whole repair process, which is regarded the rate-limiting step (Collins, 1987; Shivji et al., 1992). It involves proteins that are rather active in the repair of DNA damage, unlike post-incision complexes that take part also in the replication or transcription of DNA. The extract is not able to perform the synthetic stages of repair, unless deoxyribonucleotides, and ATP are provided (Collins et al., 1994). 


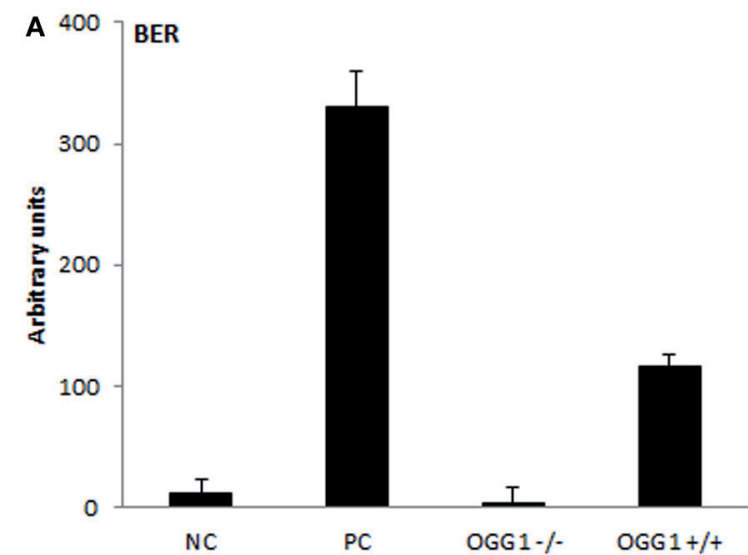

FIGURE 3 | Testing the extracts from DNA repair gene knock-out cells. Measurement of BER and NER activities in knock-out cells and wild-type control cells of the same origin. For (A) BER assay extracts were isolated from $\mathrm{OGG} 1^{-/-}$and $\mathrm{OGG} 1^{+/+}$mice livers; negative control (NC) represents

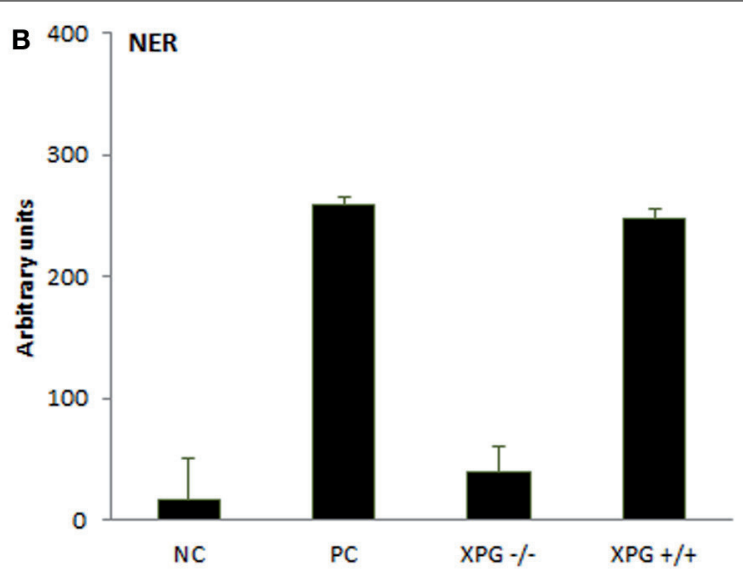

incubation with buffer only and positive control (PC) incubation with Fpg. For (B) NER assay extracts were isolated from $\mathrm{XPG}^{-/-}$and $\mathrm{XPG}^{+/+}$hamster ovarian cancer cells $\mathrm{CHO} A A 8$, and $\mathrm{NC}$ and $\mathrm{PC}$ represent incubation with buffer and Endo $\mathrm{V}$, respectively. Data represent means $\pm S D$ of duplicate measurements.
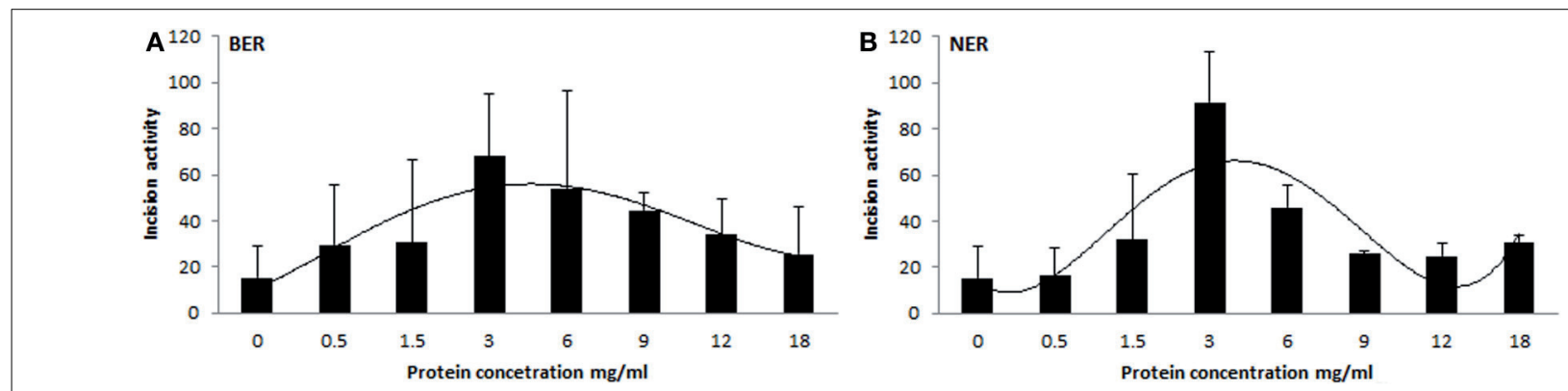

FIGURE 4 | Relationship between protein concentration of extract and its activity. Different protein concentrations of tissue extracts plotted against their BER (A) and NER (B) activities. Each experimental point represents mean $\pm S D$ of duplicate measurements.

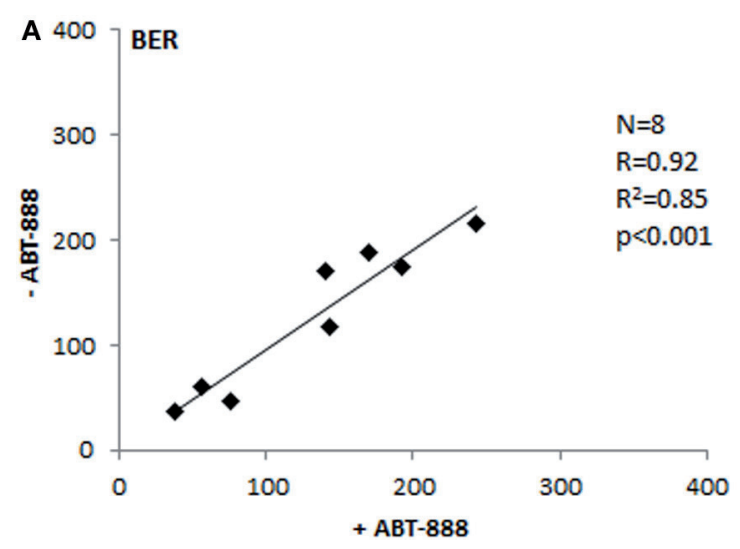

FIGURE 5 | Testing the inhibition of post-incision phase. Comparison of BER (A) and NER (B) activities between extracts treated with inhibitors of polymerization and the same extracts not suppressed for the polymerization

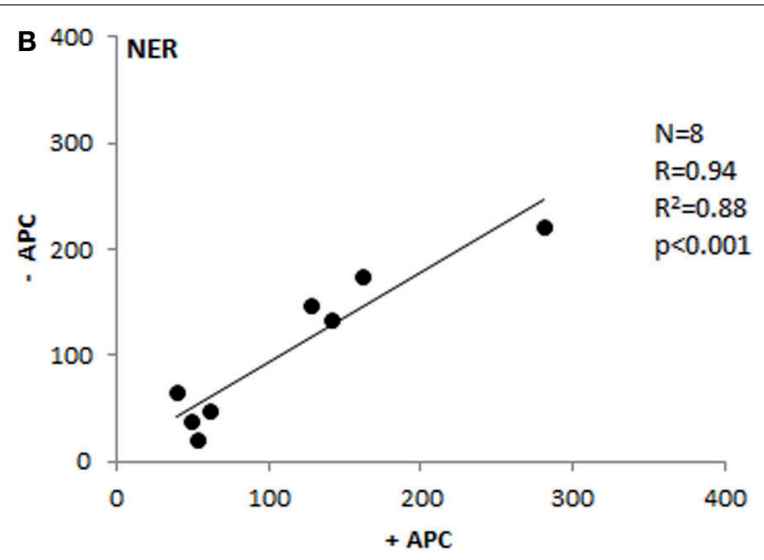

activity (Spearman's correlation coefficient). ABT-888, inhibitor of Poly-(ADP)-ribose polymerase; APC, aphidicolin - inhibitor of DNA polymerase delta.

particular lesion; however the 8-oxoguanine DNA glycosylase (OGG1) is the primary enzyme recognizing and incising this lesion. Among others, NEIL1 and NEIL2 have marginal activity in repair of this lesion, NTH1 repairs free 8-oxoG and MUTYH recognizes adenine already mispaired with 8-oxoG. Therefore, BER 


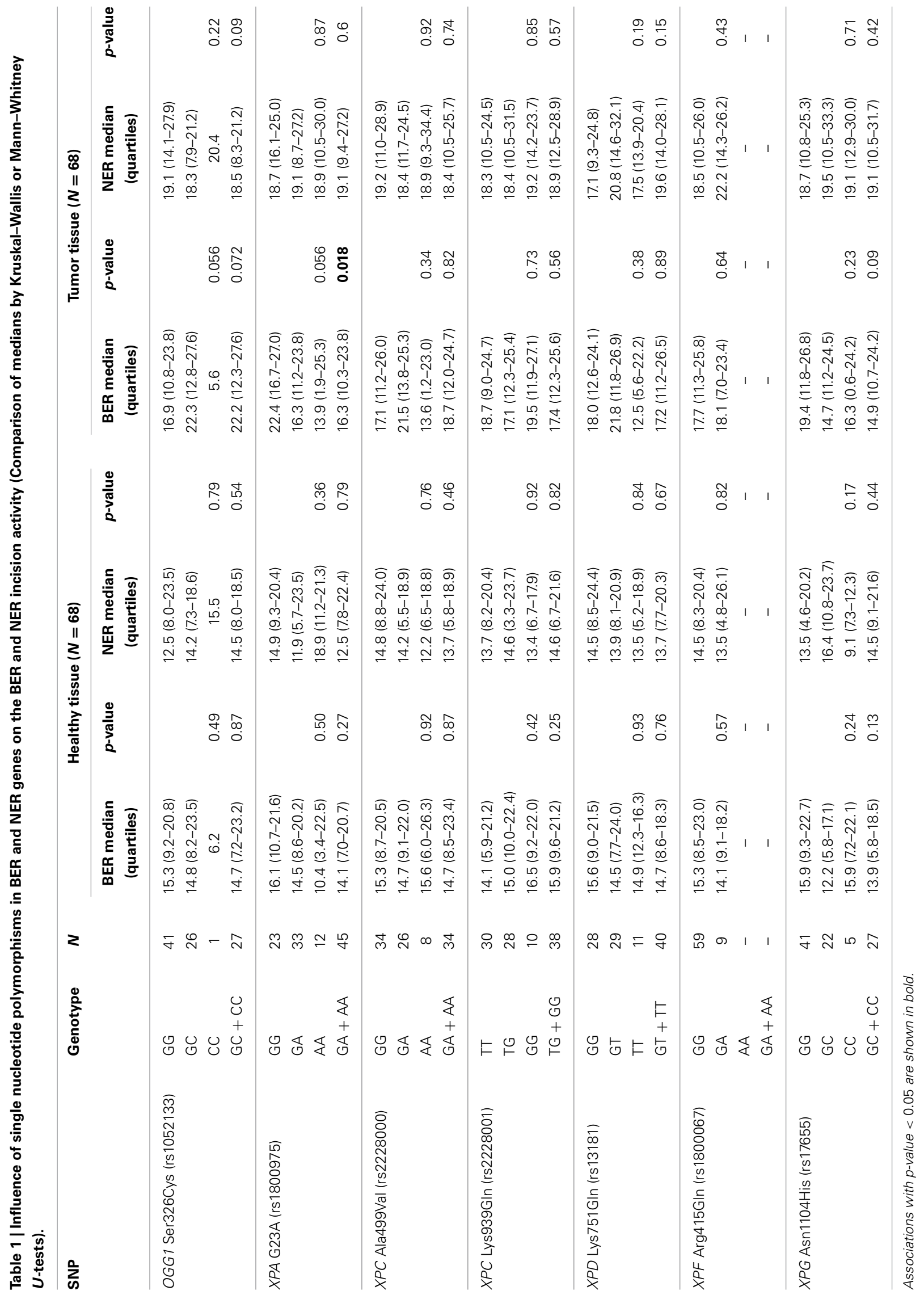


activity, as measured in vitro in our assay toward Ro-induced lesions, is mainly reflecting the activity of the BER glycosylase OGG1. In contrast to BER, NER enzymes work in large complexes and the minimal requirement for the incision comprises at least 20 proteins.

The majority of BER and NER genes are polymorphic in the population, and over $50 \%$ of them have functionally relevant amino acid changes. By applying SIFT or PolyPhen algorithms, several SNPs are predicted to be possibly damaging, damaging, or deleterious, by means of protein function (Xi et al., 2004) and these in silico characterizations are also supported by a range of epidemiological and in vitro studies. In this study, functional SNPs in BER genes were represented by the commonly studied OGG1 Ser326Cys, while NER genes were represented by XPA G23A, XPC Ala499Val and Lys939Gln, XPD Lys751Gln, XPG Asn1104His and XPF Arg415Gln. All of these potentially functional SNPs were genotyped in the cohort of 68 individuals and their effects on BER and NER activity of colorectal tissues were studied. None of the studied SNPs showed any direct association with DNA repair activity in either healthy or tumor tissues, except for XPA 23A allele that was associated with lower BER in tumor tissues only (Table 1). An association of XPA G23A genotype with BER activity in PBMC was observed by Dusinska et al. (2006), although in a relationship opposite to that found by us. Conflicting findings were obtained from studies with Xpadeficient mice, where XPA seems not to play an important role in oxidative DNA damage repair (Melis et al., 2013). We are aware of low statistical power and risk of type 2 error due to the low number of individuals carrying variant alleles. Nonetheless, reports on genetic variability in relation to DNA repair activity of target tissue (i.e., tissue other than blood) were missing until now.

\section{Is protein activity related to level of gene transcription?}

We have measured the amount of OGG1 transcripts in paired tumor-healthy human colorectal tissues and compared it with the BER-related incision activity, which represents mainly OGG1 activity. The activity of the protein was completely independent of the mRNA quantity, with Pearson's correlation coefficient close to 0 for both tumor and normal tissue (Figure 6). Lack of a relationship between mRNA level and activity of the protein is not rare in the literature (Damia et al., 1998; Vogel et al., 2000; Paz-Elizur et al., 2007; Stevens et al., 2008; Slyskova et al., 2012a,b). On the contrary, there is growing evidence on the important role of regulation of enzyme activity at posttranscriptional and post-translational levels. OGG1 is a housekeeping gene of constitutive expression independent of the cell cycle (Dhenaut et al., 2000). It might be regulated via two CpG islands located in the promoter region; however, this was not the case in our samples since none of 88 samples exhibited C methylation in OGG1 promoter (Slyskova et al., 2012b). OGG1 has eight alternative isoforms/splicing variants of two major groups; type 1 acts in the nucleus, and type 2 in the mitochondria (Boiteux and Radicella, 2000). However, this would not serve as

Table 2 | Correlation of expression of 17 genes involved in NER pre-incision complex with overall NER incision activity (Pearson's correlation coefficient).

\begin{tabular}{|c|c|c|c|c|}
\hline \multirow[t]{3}{*}{ Gene } & \multicolumn{4}{|c|}{ NER activity } \\
\hline & \multicolumn{2}{|c|}{ Healthy tissue $(N=44)$} & \multicolumn{2}{|c|}{ Tumor $(N=44)$} \\
\hline & $\boldsymbol{R}$ & $p$-value & $\boldsymbol{R}$ & $p$-value \\
\hline $\mathrm{CCNH}$ & -0.146 & 0.35 & -0.028 & 0.86 \\
\hline CDK7 & -0.012 & 0.94 & 0.320 & 0.036 \\
\hline$C S B$ & -0.101 & 0.51 & -0.039 & 0.80 \\
\hline$D D B 1$ & -0.158 & 0.31 & -0.094 & 0.54 \\
\hline$D D B 2$ & -0.200 & 0.19 & -0.183 & 0.23 \\
\hline ERCC1 & -0.133 & 0.39 & -0.146 & 0.35 \\
\hline$L I G 1$ & 0.086 & 0.58 & 0.123 & 0.43 \\
\hline MNAT1 & -0.125 & 0.42 & -0.094 & 0.54 \\
\hline$R A D 23 B$ & -0.030 & 0.85 & 0.190 & 0.22 \\
\hline RPA 1 & -0.079 & 0.61 & -0.05 & 0.75 \\
\hline RPA2 & 0.007 & 0.96 & 0.067 & 0.67 \\
\hline RPA3 & -0.039 & 0.80 & 0.225 & 0.14 \\
\hline$X P A$ & -0.168 & 0.28 & -0.246 & 0.11 \\
\hline$X P B$ & -0.055 & 0.73 & -0.009 & 0.96 \\
\hline$X P C$ & -0.062 & 0.69 & -0.004 & 0.98 \\
\hline$X P D$ & -0.164 & 0.29 & -0.001 & 0.99 \\
\hline$X P F$ & -0.136 & 0.38 & -0.091 & 0.56 \\
\hline
\end{tabular}

Associations with p-value $<0.05$ are shown in bold.
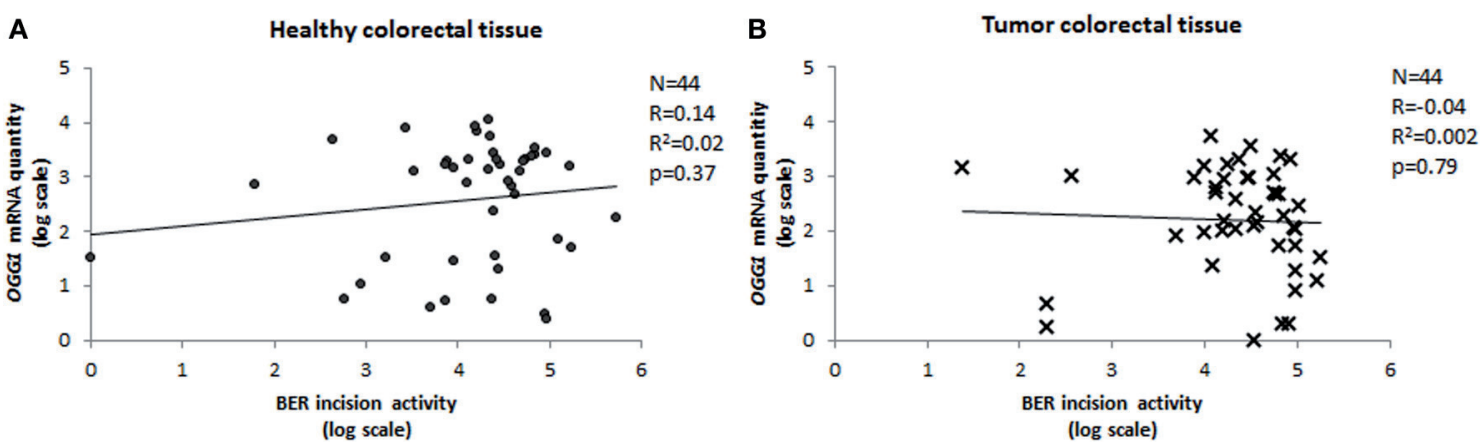

FIGURE 6 | Correlation between OGG1 expression and BER incision activity. Relative quantity of OGG1 transcripts measured in 44 paired healthy (A) and tumor (B) tissue samples plotted against BER activity (Pearson's correlation coefficient). 
an explanation of missing mRNA quantity/protein activity correlation either, since all transcript variants have been covered in the assay. Nevertheless, other mechanisms might regulate gene activity; for example 160 microRNAs identified up to now are able to bind to OGG1 transcripts (http://bioinformatics.ekmd.huji. ac.il/reptar/gene_report.php?species=human\&id=12458). Above all, two post-translational modifications-phosphorylation and nitrosylation-modulate the final protein activity. Another source of variability might be represented by protein-protein interactions (Fan and Wilson, 2005).

The mRNA expression of the majority of proteins forming the pre-incision complex of NER was also measured and plotted against the overall NER activity. The expression level of none of the 17 studied genes was significantly associated with the NER incision activity, except for CDK7 protein involved in TFIIH complex in the tumor tissue only (Table 2). DNA damage recognition and incision is much more complex in NER as compared to BER. In BER, usually only 1 or 2 proteins are able to recognize and incise damage from DNA, while in NER, the whole complex of many proteins is required for lesion removal. NER proteins work in an interactive downstream manner and are known to be substantially regulated at a post-translational level, which makes the lack of correlation of single gene expression and endpoint NER incision activity understandable. According to our results and the results of other research groups (Damia et al., 1998; Vogel et al., 2000; Paz-Elizur et al., 2007; Stevens et al., 2008; Hanova et al., 2011; Slyskova et al., 2012b), expression analysis of single genes is not a sufficiently informative marker of activity of protein or protein complexes.

\section{CONCLUDING REMARKS}

Analyzing DNA repair activity in target tissue might represent an important step toward individualized anti-cancer therapy. Previously we have shown that activities of the BER and NER pathways positively correlate between white blood cells and healthy colon tissue, but not between blood cells and tumor (Slyskova et al., 2012b). Therefore, methods for assessing functionality of DNA repair in solid tissues are warranted. New comet-based repair assays are reliable, simple, fast, and of low cost. An advanced medium-throughput format is suitable for large epidemiological studies. We have also shown that measuring DNA repair activity is not easily replaceable by a genomic or transcriptomic approach, but should be applied with the latter techniques in a complementary manner.

\section{FUNDING}

This work was supported by CZ: GACR: GAP 304/12/1585. Sabine A. S. Langie was supported by the Centre for Brain Ageing and Vitality, which is funded through the Lifelong Health and Wellbeing cross council initiative by the MRC, BBSRC, EPSRC, and ESRC in the UK, and currently Sabine A. S. Langie is the beneficiary of a post-doctoral grant from the AXA Research Fund.

\section{ACKNOWLEDGMENTS}

Authors are grateful to prof. Rudolf Stetina for providing BERdeficient and proficient mouse livers and to prof. Fabrizio Palitti for NER-deficient and proficient CHO AA8 cells.

\section{REFERENCES}

Azqueta, A., Gutzkow, K. B., Priestley, C. C., Meier, S., Walker, J. S., Brunborg, G., et al. (2012). A comparative performance test of standard, mediumand high-throughput comet assays. Toxicol. In Vitro 27, 768-773. doi: 10.1016/j.tiv.2012.12.006

Azqueta, A., Meier, S., Priestley, C., Gutzkow, K. B., Brunborg, G., Sallette, J., et al. (2011). The influence of scoring method on variability in results obtained with the comet assay. Mutagenesis 26, 393-399. doi: 10.1093/mutage/geq105

Boiteux, S., and Radicella, J. P. (2000). The human OGG1 gene: structure, functions, and its implication in the process of carcinogenesis. Arch. Biochem. Biophys. 377, 1-8. doi: 10.1006/abbi.2000.1773

Cleaver, J. E., Lam, E. T., and Revet, I. (2009). Disorders of nucleotide excision repair: the genetic and molecular basis of heterogeneity. Nat. Rev. Genet. 10, 756-768. doi: $10.1038 / \mathrm{nrg} 2663$

Collins, A. (1987). Estimates of the rate of ligation during excision repair of ultraviolet-damaged DNA in mammalian cells. Biochim. Biophys. Acta. 908, 103-106. doi: 10.1016/0167-4781(87)90027-3

Collins, A. R., Azqueta, A., and Langie, S. A. (2012). Effects of micronutrients on DNA repair. Eur. J. Nutr. 51, 261-279. doi: 10.1007/s00394-012-0318-4

Collins, A. R., Dusinska, M., Horvathova, E., Munro, E., Savio, M., and Stetina, R. (2001). Inter-individual differences in repair of DNA base oxidation, measured in vitro with the comet assay. Mutagenesis 16, 297-301. doi: 10.1093/mutage/16.4.297

Collins, A. R., Fleming, I. M., and Gedik, C. M. (1994). In vitro repair of oxidative and ultraviolet-induced DNA damage in supercoiled nucleoid DNA by human cell extract. Biochim. Biophys. Acta. 1219, 724-727. doi: 10.1016/01674781(94)90236-4

Damia, G., Guidi, G., and D’Incalci, M. (1998). Expression of genes involved in nucleotide excision repair and sensitivity to cisplatin and melphalan in human cancer cell lines. Eur. J. Cancer 34, 1783-1788. doi: 10.1016/S09598049(98)00190-7

Dhenaut, A., Boiteux, S., and Radicella, J. P. (2000). Characterization of the hOGG1 promoter and its expression during the cell cycle. Mutat. Res. 461, 109-118. doi: 10.1016/S0921-8777(00)00042-2

Dusinska, M., Dzupinkova, Z., Wsolova, L., Harrington, V., and Collins, A. R. (2006). Possible involvement of XPA in repair of oxidative DNA damage deduced from analysis of damage, repair and genotype in a human population study. Mutagenesis 21, 205-211. doi: 10.1093/mutage/gel016

Fan, J., and Wilson, D. M. 3rd. (2005). Protein-protein interactions and posttranslational modifications in mammalian base excision repair. Free Radic. Biol. Med. 38, 1121-1138. doi: 10.1016/j.freeradbiomed.2005.01.012

Hanova, M., Stetina, R., Vodickova, L., Vaclavikova, R., Hlavac, P., Smerhovsky, Z., et al. (2011). Modulation of DNA repair capacity and mRNA expression levels of XRCC1, hOGG1 and XPC genes in styrene-exposed workers. Toxicol. Appl. Pharmacol. 248, 194-200. doi: 10.1016/j.taap.2010.07.027

Hu, H., and Gatti, R. A. (2011). MicroRNAs: new players in the DNA damage response. J. Mol. Cell Biol. 3, 151-158. doi: 10.1093/jmcb/mjq042

Langie, S. A., Cameron, K. M., Waldron, K. J., Fletcher, K. P., von Zglinicki, T., and Mathers, J. C. (2011). Measuring DNA repair incision activity of mouse tissue extracts towards singlet oxygen-induced DNA damage: a comet-based in vitro repair assay. Mutagenesis 26, 461-471. doi: 10.1093/mutage/ger005

Langie, S. A., Knaapen, A. M., Brauers, K. J., van Berlo, D., van Schooten, F. J., and Godschalk, R. W. (2006). Development and validation of a modified comet assay to phenotypically assess nucleotide excision repair. Mutagenesis 21, 153-158. doi: 10.1093/mutage/gel013

Langie, S. A., Kowalczyk, P., Tudek, B., Zabielski, R., Dziaman, T., Olinski, R., et al. (2010). The effect of oxidative stress on nucleotide-excision repair in colon tissue of newborn piglets. Mutat. Res. 695, 75-80. doi: 10.1016/j.mrgentox.2009.12.005

Lord, C. J., and Ashworth, A. (2012). The DNA damage response and cancer therapy. Nature 481, 287-294. doi: 10.1038/nature10760

Melis, J. P., van Steeg, H., and Luijten, M. (2013). Oxidative DNA damage and nucleotide excision repair. Antioxid. Redox Signal. 18, 2409-2419. doi: 10.1089 /ars.2012.5036

Nouspikel, T. (2011). Multiple roles of ubiquitination in the control of nucleotide excision repair. Mech. Ageing Dev. 132, 355-365. doi: 10.1016/j.mad.2011. 03.003

Olive, P. L., and Banath, J. P. (2006). The comet assay: a method to measure DNA damage in individual cells. Nat. Protoc. 1, 23-29. doi: 10.1038/nprot.2006.5 
Pallis, A. G., and Karamouzis, M. V. (2010). DNA repair pathways and their implication in cancer treatment. Cancer Metastasis Rev. 29, 677-685. doi: 10.1007/s10555-010-9258-8

Paz-Elizur, T., Elinger, D., Leitner-Dagan, Y., Blumenstein, S., Krupsky, M., Berrebi, A., et al. (2007). Development of an enzymatic DNA repair assay for molecular epidemiology studies: distribution of OGG activity in healthy individuals. DNA Rep. (Amst.) 6, 45-60. doi: 10.1016/j.dnarep.2006.08.003

Ricceri, F., Matullo, G., and Vineis, P. (2012). Is there evidence of involvement of DNA repair polymorphisms in human cancer? Mutat. Res. 736, 117-121. doi: 10.1016/j.mrfmmm.2011.07.013

Shaposhnikov, S., Azqueta, A., Henriksson, S., Meier, S., Gaivao, I., Huskisson, N. H., et al. (2010). Twelve-gel slide format optimised for comet assay and fluorescent in situ hybridisation. Toxicol. Lett. 195, 31-34. doi: 10.1016/j.toxlet.2010.02.017

Shivji, K. K., Kenny, M. K., and Wood, R. D. (1992). Proliferating cell nuclear antigen is required for DNA excision repair. Cell 69, 367-374. doi: 10.1016/00928674(92)90416-A

Slyskova, J., Naccarati, A., Pardini, B., Polakova, V., Vodickova, L., Smerhovsky, Z., et al. (2012a). Differences in nucleotide excision repair capacity between newly diagnosed colorectal cancer patients and healthy controls. Mutagenesis 27, 225-232. doi: 10.1093/mutage/ger088

Slyskova, J., Korenkova, V., Collins, A. R., Prochazka, P., Vodickova, L., Svec, J., et al. (2012b). Functional, genetic, and epigenetic aspects of base and nucleotide excision repair in colorectal carcinomas. Clin. Cancer Res. 18, 5878-5887. doi: 10.1158/1078-0432.CCR-12-1380

Stevens, E. V., Nishizuka, S., Antony, S., Reimers, M., Varma, S., Young, L., et al. (2008). Predicting cisplatin and trabectedin drug sensitivity in ovarian and colon cancers. Mol. Cancer Ther. 7, 10-18. doi: 10.1158/1535-7163.MCT-070192
Vogel, U., Dybdahl, M., Frentz, G., and Nexo, B. A. (2000). DNA repair capacity: inconsistency between effect of over-expression of five NER genes and the correlation to mRNA levels in primary lymphocytes. Mutat. Res. 461, 197-210. doi: 10.1016/S0921-8777(00)00051-3

Wu, X., Spitz, M. R., Amos, C. I., Lin, J., Shao, L., Gu, J., et al. (2006). Mutagen sensitivity has high heritability: evidence from a twin study. Cancer Res. 66, 5993-5996. doi: 10.1158/0008-5472.CAN06-1007

Xi, T., Jones, I. M., and Mohrenweiser, H. W. (2004). Many amino acid substitution variants identified in DNA repair genes during human population screenings are predicted to impact protein function. Genomics 83, 970-979. doi: 10.1016/j.ygeno.2003.12.016

Conflict of Interest Statement: The authors declare that the research was conducted in the absence of any commercial or financial relationships that could be construed as a potential conflict of interest.

Received: 17 March 2014; accepted: 16 April 2014; published online: 23 May 2014. Citation: Slyskova J, Langie SAS, Collins AR and Vodicka P (2014) Functional evaluation of DNA repair in human biopsies and their relation to other cellular biomarkers. Front. Genet. 5:116. doi: 10.3389/fgene.2014.00116

This article was submitted to Genomic Assay Technology, a section of the journal Frontiers in Genetics.

Copyright (c) 2014 Slyskova, Langie, Collins and Vodicka. This is an open-access article distributed under the terms of the Creative Commons Attribution License (CC BY). The use, distribution or reproduction in other forums is permitted, provided the original author(s) or licensor are credited and that the original publication in this journal is cited, in accordance with accepted academic practice. No use, distribution or reproduction is permitted which does not comply with these terms. 